УДК 622.28.044:622.831

ПРО ОДИН МЕТОД ОЦІНКИ ВАНТАЖОСПРОМОЖНОСТІ МЕТАЛОПОЛІМЕРНОГО АНКЕРУ ВІД ВПЛИВУ ЙОГО ПАРАМЕТРІВ

${ }^{1}$ Ларіонов Г.І., ${ }^{1}$ Ларіонов М.Г.

${ }^{1}$ Інститут геотехнічної механіки ім. М.С. Полякова НАН України

\title{
ABOUT ONE METHOD OF EVALUATION OF FREIGHT FORMALITIES OF METAL POLYMER ANKER FROM THEIR EFFECTS OF ITS PARAMETERS ${ }^{1}$ Larionov H.I., 'Larionov M.H.
}

${ }^{1}$ Institute of Geotechnical Mechanics named by N. Poljakov NAS of Ukraine

\section{ОБ ОДНОМ МЕТОДЕ ОЦЕНКИ ГРУЗОСПОСОБНОСТИ МЕТАЛЛОПОЛИМЕРНОГО АНКЕРА ОТ ВЛИЯНИЯ ЕГО ПАРАМЕТРОВ \\ 'Ларионов Г.И., 'Ларионов М.Г. \\ ${ }^{1}$ Институт геотехнической механики им. Н.С. Полякова НАН Украины}

Анотація. В роботі розглянуто застосування точкової оцінки результатів, отриманих чисельними методами. Результат точкової оцінки являє собою аналітичний вираз у вигляді добутку незалежних функцій однієї змінної. Вираз застосовується для аналізу поведінки функції в околиці досліджуваної точки. Як модельні, для демонстрації запропонованого методу розглянуті завдання про подання ряду елементарних функцій з оцінкою їх похибок. Наведено приклад використання зазначеного підходу до технічного завдання. Зроблено висновок про можливість застосування зазначеного підходу до вирішення важливої наукової проблеми визначення кроку розстановки анкерів з урахуванням механізму передачі в системі «анкер-яка фіксує суміш-гірська порода». Метод послідовної апроксимації, запропонований для визначення закономірностей між параметрами системи, підтвердив свою працездатність.

Відносні похибки для більшості параметрів не перевищують 7 \%, що є підтвердженням працездатності алгоритму, з одного боку, і можливості користування спрощеними формулами для інженерних розрахунків, з другого. Система параметрів для оцінки напружено-деформованого стану визначається шляхом вирішення двох задач. 3 рішення модифікованої узагальненої задачі М.Є. Жуковського визначався розподіл дотичних напружень на поверхні свердловини. Далі воно використовувалося в якості граничних умов для визначення зони поширення напружено-деформованого стану в околиці анкера. Такий підхід дозволив отримати залежність кроку розстановки анкерів з урахуванням глибини залягання гірничої виробки, попереднього натягу анкерів, довжини, його діаметру, інтенсивності дотичних напружень. Радіус впливу є пропорційним жорсткості системи, що збігається з висновками інших вчених про обернений характер залежності від довжини анкеру і підтверджує правильність отриманої залежності.

Ключові слова: металополімерний анкер, оцінка, напружено-деформований стан, система, незалежні функції, радіус впливу.

Передмова. Результати аналізу математичних моделей найчастіше являють собою масиви чисельних даних, які отримані шляхом використання комплексів програм реалізованих на мовах програмування.

На етапі аналізу результатів апробації математичної моделі, існує потреба у 3’ясуванні впливу того чи іншого параметру та взаємозв'язок між ними. Запропонований алгоритм дозволяє суттєво зменшити обчислювальні витрати. Так, замість обчислення значень функції на сітці параметрів, вони обраховуються лише на координатних лініях. Відтворена функція, у цьому випадку будується у вигляді добутку елементарних функцій, кожна з яких є функцією однієї змінної.

Будь-який процес дослідження взагалі проводиться з допомогою імітаційних або математичних моделей (MM) і може бути представлений у вигляді «чорної скриньки» (рис.1). 
ISSN 1607-4556 (Print), ISSN 2309-6004 (Online) Геотехнічна механіка. 2018. №142

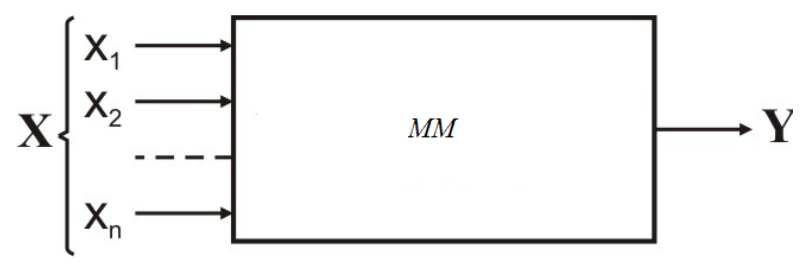

Рисунок 1 - Узагальнена модель у вигляді чорної скриньки

На рисунку $1 X\left(x_{1}, x_{2}, \ldots x_{n}\right)$ - це параметри керування або змінні моделі: $Y$ результуючий фактор або аналітична функція $Y=Y\left(x_{1}, x_{2}, \ldots x_{n}\right)$ форму якої необхідно відтворити за даними отриманими після комп'ютерної обробки. Модель може бути представлена як фізичними приладами, системами диференціальних рівнянь, математичними формулами та обчислювальними програмами або Пакетами Прикладних Програм (ППП) які ії реалізують.

Дані досліджень 3 допомогою ММ, як правило, представляють собою матриці чисел або таблиці числових даних. Відтворення функцій представлених у вигляді числових даних здійснюється на сітці параметрів.

Для складних задач отримання значень функцій на сітці параметрів потребує значних витрат машинного часу, що робить проблему відтворення функцій практично неможливою. Проблема відтворення функцій без використання параметрів на сітці буде актуальною не дивлячись на обчислювальні швидкості сучасних комп'ютерів.

Метод послідовної апроксимації (МПА) [1] дозволяє представляти відтворену функцію в аналітичному вигляді (у вигляді добутку функцій кожна 3 яких залежить від однієї змінної) коли вона існує в табличній формі в околі точки (рис.2).

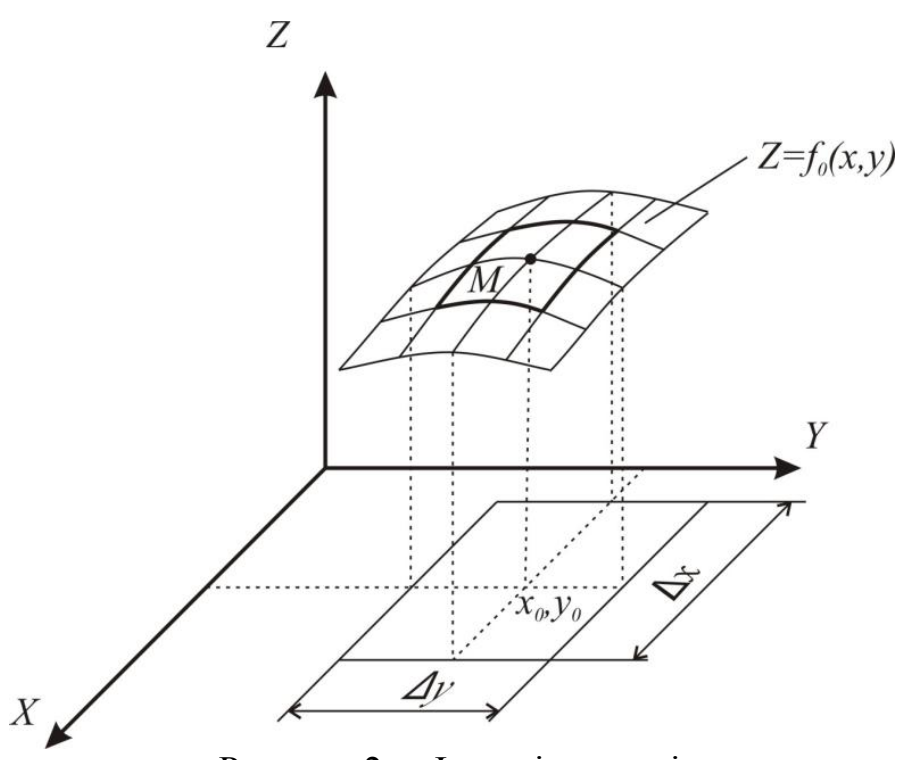

Рисунок 2 - Функція моделі

Успішне використання МПА в задачах геотехнічної механіки надихнуло авторів сформулювати теорему про існування такого представлення для більш ширшого кола задач. 
ISSN 1607-4556 (Print), ISSN 2309-6004 (Online) Геотехнічна механіка. 2018. №142

TEOРЕМА: Нехай існує $F(X)=F\left(x_{1}, x_{2} \ldots x_{n}\right)$ яка $€$ визначеною і неперервною у замкнутій області $\bar{D}$. Припустимо, що $F$ є обмеженою і має частинні похідні першого порядку обмежені у $\bar{D}$.

Тоді в околі точки $X_{0}=\left(x_{1}^{0}, x_{2}^{0}, x_{n}^{0}\right) \in \bar{D}$ функція $F(X)$ може бути представлена у вигляді

$$
F(X) \approx \varphi\left(x_{1}, \ldots, x_{n}\right)=\alpha_{n} \prod_{i=1}^{n} g_{i}\left(x_{i}\right)
$$

де $g_{i}\left(x_{i}\right)$ - функції апроксимації для $f_{1}, f_{2}, \ldots, f_{n}$ які задані у табличній формі, а $\alpha_{\mathrm{n}}$ - коефіцієнт апроксимації, який визначається у відповідності до формули

$$
\alpha_{n}=\frac{F\left(x_{1}{ }^{0}, x_{2}{ }^{0}, x_{3}{ }^{0}, \ldots x_{n}{ }^{0}\right)}{g_{1}\left(x_{1}{ }^{0}\right) g_{2}\left(x_{2}{ }^{0}\right) \ldots g_{n}\left(x_{n}{ }^{0}\right)} \text {. }
$$

Зазначені функції визначаються наступним чином

$$
f_{1}\left(x_{1}\right)=F\left(x_{1}, x_{1}^{0}, \ldots x_{n}^{0}\right), f_{2}\left(x_{2}\right)=F\left(x_{1}^{0}, x_{2}, \ldots x_{n}^{0}\right), \ldots f_{n}\left(x_{n}\right)=F\left(x_{1}^{0}, x_{2}^{0}, \ldots x_{n}\right) .
$$

Як засвідчує досвід використання вказаного підходу представлення функції $F(X)=F\left(x_{1}, x_{2} \ldots x_{n}\right)$ в околі точки $X_{0}=\left(x_{1}^{0}, x_{2}^{0}, x_{n}^{0}\right) \in \bar{D}$ має достатню для інженерних розрахунків точність на всій області визначення $\bar{D}$.

Алгоритм МПА може бути представлений послідовністю наступних кроків [4].

Крок 1. Обираємо точку на області визначення функції $M=M\left(x_{1}^{0}, x_{2}^{0}, \ldots, x_{n}^{0}\right), M \in \bar{D}$

Крок 2. створюємо функцію $f_{1}\left(x_{1}\right)=F\left(x_{1}, x_{2}^{0}, \ldots, x_{n}^{0}\right)$;

Крок 3.знаходимо вид функції $g_{1}\left(x_{1}\right)$, яка $є$ апроксимацією для функції $f_{1}\left(x_{1}\right)$;

Крок 4. Знаходимо $\varphi_{1}\left(x_{1}\right)$ у відповідності до (1): $\varphi_{1}\left(x_{1}\right)=\alpha_{1} g_{1}\left(x_{1}\right)$, де $\alpha_{1}-$ коефіцієнт апроксимації;

Крок 5. Визначаємо функцію у околі точки $M$ з рівності $F\left(x_{1}\right) \approx \varphi_{1}\left(x_{1}\right)$.

Повторюємо кроки 2-5 послідовно для змінних $x_{j}(j=\overline{2, n})$ і отримуємо шукане представлення

$$
F\left(x_{1}, x_{2}, x, \ldots, x_{n}\right) \approx \varphi\left(x_{1}, x_{2}, x, \ldots, x_{n}\right)=\alpha_{n} g_{1}\left(x_{1}\right) g_{2}\left(x_{2}\right) \ldots g_{n}\left(x_{n}\right),
$$

де $\alpha_{n}$ - коефіцієнт апроксимації визначається як: 
ISSN 1607-4556 (Print), ISSN 2309-6004 (Online) Геотехнічна механіка. 2018. №142

$$
\alpha_{i}=\frac{f_{i}\left(x_{i}\right)}{\prod_{j=1}^{i} g_{j}\left(x_{j}{ }^{0}\right)} \quad \text { та } \quad \alpha_{n}=\frac{F\left(x_{1}{ }^{0}, x_{2}{ }^{0}, x_{3}{ }^{0}, \ldots x_{n}{ }^{0}\right)}{g_{1}\left(x_{1}{ }^{0}\right) g_{2}\left(x_{2}{ }^{0}\right) . . g_{n}\left(x_{n}{ }^{0}\right)}
$$

Звернути увагу:

1. Вибір точки $\boldsymbol{M}=\boldsymbol{M}\left(x_{1}^{\mathrm{o}}, x_{2}^{\mathrm{o}}, \ldots, x_{n}^{\mathrm{o}}\right), \boldsymbol{M} \in \overline{\boldsymbol{D}}$ значно впливає на вид відтвореної функції і впливає на вид обраної функції у іï околі. Коли топографія функції невідома пропонується обирати точку в центрі області визначення і координати визначати згідно формул $x_{j}=\left(b_{j}-a_{j}\right) / 2$, де $a_{j}$ i $b_{j}$ являють собою початки та кінці інтервалу зміни параметру $x_{j}$ відповідно;

Виконання кроку 2 має мету отримання табличної форми функцій $f_{i}$. Якщо вихідна функція не визначена в аналітичному виді необхідно виконати обчислення для послідовності значень змінних 3 певним кроком. Вибір величини кроку кожної змінної для обчислення значень функції значною мірою впливає на точність відтворюваної функції. Вибір величин кроків для змінних залежить від вибору області їі визначення та знань дослідника особливостей фізики процесу, що досліджується.

МПА не має обмежень на вибір класу функцій у представлені функції у вигляді добутку функцій, що залежать від однієї змінної. Широке застосування методу на практиці отримав клас степеневих функцій. Основними особливостями їх застосування $\epsilon$; по перше отримати показник впливу параметру на функцію, по-друге, дозволяє визначити фізичний зміст процесу, який описується функцією. Як результат вищенаведеного буде відтворено вихідну функцію у вигляді добутку незалежних функцій.

В роботі [3] було наведено і доведено теорему про оцінку верхньої межі похибки аналітичної форми відтвореного представлення

$$
\left\|F-\varphi_{*}\right\| \leq C_{F}\left(\sum_{i=1}^{n}\left|\Delta_{x_{i}}\right|\right)
$$

де $\left|\Delta_{x_{i}^{0}}\right|$ - довжина інтервалу $\Delta_{x_{i}^{0}},(i=\overline{1, n}) ; C_{F}-$ довільна стала, яка залежить від функції $F$ і не залежить від $n$. Так для $n=2$ така стала має вид

$$
C_{F}=K\left(1+\frac{1}{\left|F\left(x_{1}^{0}, x_{2}^{0}\right)\right|}+\frac{N^{3}}{\mid F\left(x_{1}^{0}, x_{2}^{0}\right)^{3}}+3 N\right)
$$

де $\Delta_{x_{i}}=\left[a_{i}, b_{i}\right], a_{i}+b_{i}=2 x_{i}^{0}(\boldsymbol{i}=\overline{\mathbf{1 , n}}) ; a_{i}$ і $b_{i}$ - довільні дійсні числа; $N$ і $K-$ довільні додатні сталі.

Таким чином, очевидно, що клас функцій, який використовується, є досить широким. Але вся робота, як випливає із наведеного, виконана для відтворення 
у околі точки із області визначення функції. Що зробити, щоб таке представлення функції було б чинним на всій області визначення? Досвід використання такого представлення показує, що рішення практичних задач може бути розширено на всю область визначення функції. Не дивлячись на той факт, що похибки такого представлення зростають при наближенні до ії границі та вони не перевищують величину 5-7\%, що $є$ достатнім для інженерних розрахунків. Таким чином метод оцінки впливу являє собою відтворення рішення задачі (коли вона існує у вигляді таблиць чисел ) у вигляді добутку степеневих функцій і порівнянні їх показників. Чим більший показник степені, тим сильніший влив параметра на функцію.

Для апробації запропонованого методу відтворення функції скористаємося відомою методикою [1]. Згідно $з$ нею для апробації методів відтворення функцій обирають функцію, задану в аналітичній формі. За цією формулою розраховується ряд точок. Маючи точки (тобто функцію, задану вже у табличній формі), використовують запропонований метод і отримують відтворену функцію. За результатами порівняння значень функцій в обраних точках роблять висновок про ефективність роботи методу. Для апробації методу оберемо не зовсім «зручні» для його використання функції, а саме

$$
\mathrm{f}(\mathrm{x}, \mathrm{y})=x+y ; \mathrm{x}, \mathrm{y} \in(0,1) ; \mathrm{f}(\mathrm{x}, \mathrm{y})=\sin (x+y) ; \mathrm{x}, \mathrm{y} \in(0,1) \text {. }
$$

Задача № 1. Виконаємо апробацію запропонованого методу на функції, заданої в аналітичній формі: $\mathrm{f}(\mathrm{x}, \mathrm{y})=x+y ; \mathrm{x}, \mathrm{y} \in(0,1)$. Результати порівняння відтвореної і заданої функції наведено нижче.

Етап 1. Побудова таблиці значень функції, заданої в аналітичній формі для зміних $x$ та $y$; вибір функцій для їх апроксимації; графічне порівняння результатів (рис. 3).

Результати виконання етапу 1 наведено нижче.

a)

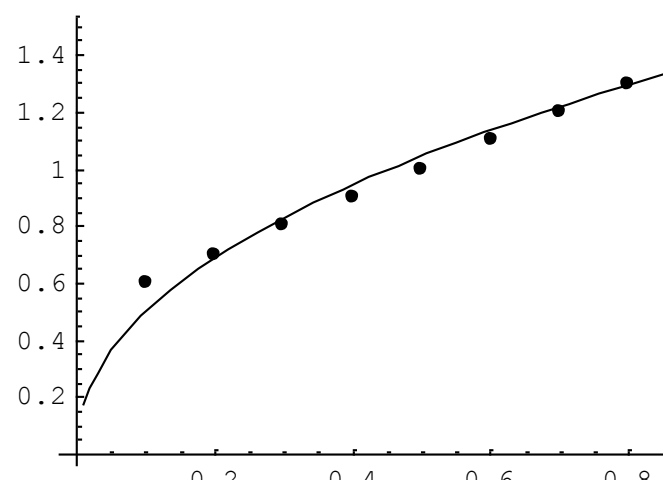

б)

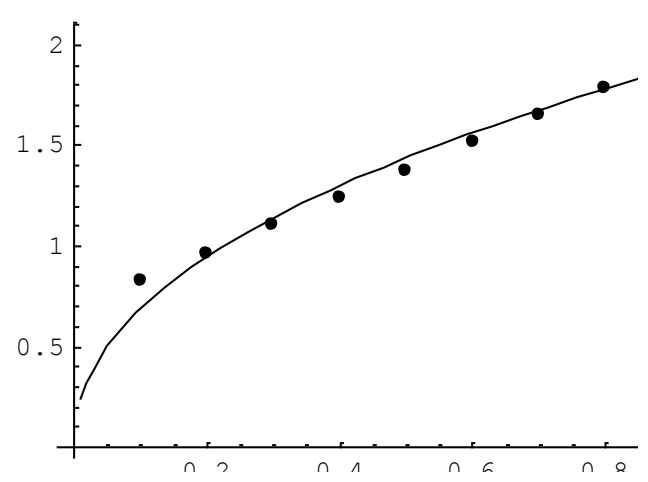

a) функція апроксимації $\mathrm{f}\left(\mathrm{x}, \mathrm{y}_{0}\right)=1,43942 x^{0,459} \mathrm{Ta} \mathrm{f}\left(\mathrm{x}, \mathrm{y}_{0}\right)=1,97882 y^{0,459}$; б) суміщений графік

Рисунок 3 - Результати побудови функції за зміни $x$ 
ISSN 1607-4556 (Print), ISSN 2309-6004 (Online) Геотехнічна механіка. 2018. №142

Остаточно, у околі точки $M\left(X_{0}\right)$ отримано відтворену функцію у вигляді формули

$$
\tilde{\mathrm{f}}(\mathrm{x}, \mathrm{y}) \approx 1,97882 x^{0,459145} y^{0,459145} .
$$

Задача № 2. Виконаємо апробацію запропонованого методу на функції,: $\mathrm{f}(\mathrm{x}, \mathrm{y})=\sin (x+y) ; \mathrm{x}, \mathrm{y} \in(0,1)$. Результати порівняння відтвореної і заданої функцій наведено нижче.

Етап 1. Побудова таблиці значень функції за зміни $x$ та у, вибір функцій апроксимації, графічне порівняння результатів (рис. 4).

a)

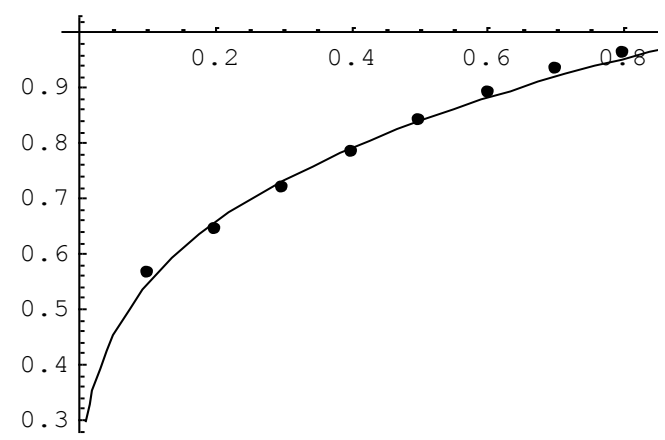

б)

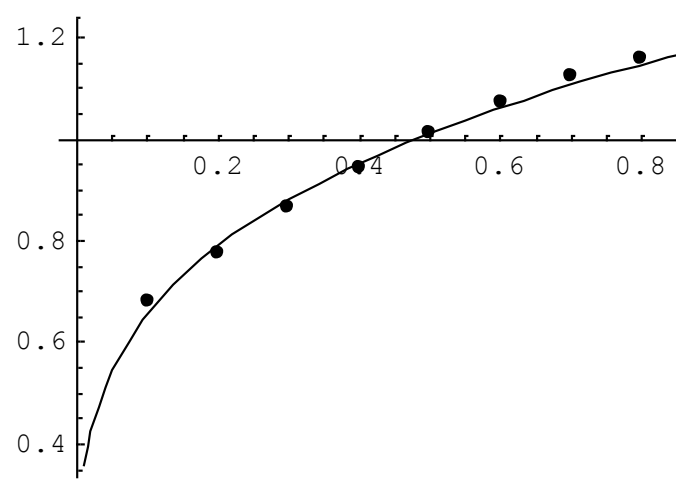

а) функція апроксимації $\mathrm{f}\left(\mathrm{x}, \mathrm{y}_{0}\right)=1,01187 x^{0.26759}$ та $\mathrm{f}\left(\mathrm{x}, \mathrm{y}_{0}\right)=1,21823 y^{0.267759}$; б) суміщений графік

Рисунок 4 - Результати побудови функції за зміни $x$

Остаточно в околі точки $M\left(X_{0}\right)$ отримано відтворену функцію у вигляді формули

$$
\tilde{\mathrm{f}}(\mathrm{x}, \mathrm{y})=1,21823 x^{0.267759} y^{0.267759} \text {. }
$$

Проблема підвищення ефективності анкерного кріплення є і буде актуальною завжди. Які параметри анкеру необхідно змінювати для того щоб досягти найбільшої потужності? Для відповіді на це питання необхідно виконати оцінку впливу кожного із них на його потужність. Для того щоб мати змогу виконати оцінку впливу конструктивних параметрів анкера на його потужність необхідно щоб його параметри ввійшли до розрахункової схеми. Такими параметрами можна вважати попереднє навантаження анкерної штанги; глибину розташування виробки, довжину та діаметри анкера та шпуру, відстань між періодичними виступами штанги анкера і поверхні шпуру; модулі пружності анкера, фіксуючої суміші та гірської породи, інтенсивність дотичних напружень та відстань між анкерами.

Найбільшої апробації в інженерній практиці набули розрахункові схеми для розрахунку технічних систем в машинобудуванні. У зв'язку з цим виникла ідея скористатися напрацьованими розрахунковими схемами для оцінки конструктивних параметрів метало полімерного анкеру. 
Так, зокрема відомо, що для передачі значних зусиль у слабкому за міцністю середовищі та зменшення зусиль на контактній поверхні «гвинт - слабкий за міцністю матеріал» використовують проміжну втулку яка містить різьбові ділянки на зовнішній і внутрішній ії поверхні. Такі конструкції отримали широку сферу застосування у різних галузях виробництва і побуті.

Металополімерний анкер, який широко використовується для кріплення гірничих виробок, за своєю природою дуже схожий на таку конструкцію. I дійсно, значні навантаження на анкерну штангу розподіляються на оточуючі гірські породи з невеликою міцністю (у порівнянні 3 міцністю матеріалу анкерної штанги) за допомогою втулки із фіксуючої суміші. Зрозуміло, що навантаження буде розподілено на більшу площу і тим самим будуть створені сприятливі умови для його передачі оточуючим гірським породам. Якби оболонка із ФС мала б на зовнішніх поверхнях різьбові ділянки, то для оцінки конструктивних параметрів можна було б використати відому розрахункову схему. Так, за різьбову ділянку анкера можна прийняти періодичні виступи на його поверхні. Як з'ясувалося, при вибурюванні шпурів під анкери в гірських породах, як правило, використовують двозубкову конструкцію бурової коронки. Вибурювання анкерних шпурів, відбувається за наявності одночасної дії відносно сталих зусиль подачі і крутного моменту штанги бурового станка, що приводять до появи на поверхні шпуру періодичних гвинтоподібних заглиблень. Після зведення анкерної штанги фіксуюча ії суміш утворює поверхню, відповідну до форми поверхні шпуру. Таким чином, система «анкерна штанга - фіксуюча суміш гірська порода» повністю може бути відтворена запропонованою М.Є. Жуковським розрахунковою схемою. Для розв'язання задачі про розподіл зусиль на контактних поверхнях цієї схеми з певністю можна застосувати розв'язок узагальненої задачі М.С. Жуковського [1] (рис. 5).

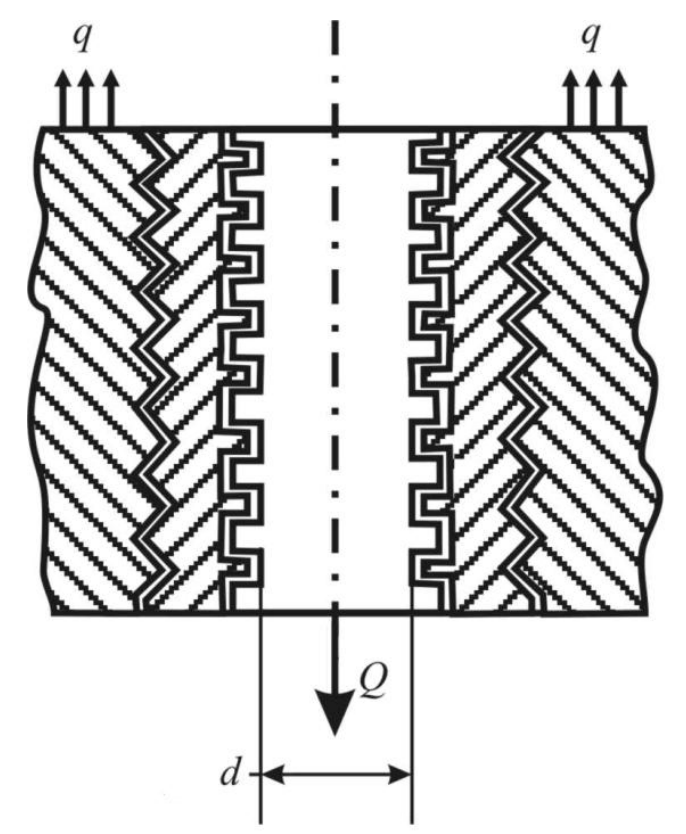

Рисунок 5 - Схема навантаження та розрахункова схема системи «анкер - фіксуюча суміш гірська порода» 
На рисунку 5 правий стрижень відображає тіло анкерної штанги, середній тіло втулки, тобто оболонки із фіксуючої суміші, а лівий стрижень - масив гірських порід. Виступи, у яких відбувається дотик стрижнів, відображають витки на поверхні анкерної штанги, втулки із ФС і гірської породи відповідно. Зусилля на витках анкерної штанги і втулки позначено як $p_{0}, p_{1}, \ldots, p_{n}$, а на витках втулки і гірської породи $-t_{0}, t_{1}, \ldots, t_{n}$. У подальшому під полем анкера будемо розуміти частину тіла, що знаходиться між двома витками.

Після модифікації узагальненої задачі М. Є. Жуковського та нескладних, але громіздких перетворень, отримаємо вираз для $t_{k}$ i $p_{k}$

$$
\begin{aligned}
& t_{k}=\frac{\lambda_{1} \lambda_{3} Q}{8 \operatorname{sh} \frac{\beta_{1}+\beta_{2}}{2} \operatorname{sh} \frac{\beta_{1}-\beta_{2}}{2}}\left[\frac{e^{-(k+1) \beta_{2}}}{\operatorname{sh} \frac{\beta_{2}}{2}}-\frac{e^{-\left(k+\frac{1}{2}\right) \beta_{1}}}{\operatorname{sh} \frac{\beta_{1}}{2}}\right] ; \\
& p_{k}=\frac{\lambda_{1} Q}{2 \operatorname{sh} \frac{\beta_{1}+\beta_{2}}{2} \operatorname{sh} \frac{\beta_{1}-\beta_{2}}{2}}\left[\operatorname{sh} \frac{\beta_{1}}{2} e^{-(k+1) \beta_{1}}-\operatorname{sh} \frac{\beta_{2}}{2} e^{-\left(k+\frac{1}{2}\right) \beta_{2}}\right]+t_{k} \text {, }
\end{aligned}
$$

де $\lambda_{1}+\lambda_{2}+\lambda_{3}+\lambda_{1} \lambda_{3}=4 \operatorname{ch} \beta_{1} \operatorname{ch} \beta_{2}-2\left(\operatorname{ch} \beta_{1}+\operatorname{ch} \beta_{2}\right)$;

$$
\begin{aligned}
& \operatorname{ch} \beta_{1}=1+\frac{\lambda_{1}+\lambda_{2}+\lambda_{3}}{4}+\sqrt{\left(1+\frac{\lambda_{1}+\lambda_{2}+\lambda_{3}}{4}\right)^{2}-\frac{\lambda_{1} \lambda_{2}}{4}} ; \\
& \operatorname{ch} \beta_{2}=1+\frac{\lambda_{1}+\lambda_{2}+\lambda_{3}}{4}-\sqrt{\left(1+\frac{\lambda_{1}+\lambda_{2}+\lambda_{3}}{4}\right)^{2}-\frac{\lambda_{1} \lambda_{2}}{4}} .
\end{aligned}
$$

Для визначення напружено-деформованого стану в околі анкерного шпуру скористаємось відомим підходом до розв'язку подібних задач (див. рис. 6).

Обгрунтуванням до застосування методів теорії пружності для визначення напружено-деформованого стану в околі анкерного шпуру є той факт, що зведення анкерного кріплення відбувається безпосередньо у грудини вибою. Це дає підстави вважати, що гірські породи біля вибою не встигли отримати пластичних деформацій і знаходяться у пружному стані.

Будемо вважати, що середовище є однорідним та ізотропним, а закріплення анкера здійснюється у глибині шпуру на відстані, що значно перевищує його діаметр. Нормальне напруження $p_{0}$ можна вважати величиною сталою, що дорівнює гірському тиску на певній глибині, а от дотичне напруження $\tau_{0}(\varsigma)$, як показують дослідження [5], суттєво змінюється по довжині анкера. Розподіл напружень в околі анкера описується основними рівняннями теорії пружності, які в вісесиметричному випадку мають вигляд [1] 
ISSN 1607-4556 (Print), ISSN 2309-6004 (Online) Геотехнічна механіка. 2018. №142

$$
\begin{aligned}
& \mu\left(\nabla^{2} U-\frac{U}{r^{2}}\right)+(\lambda+\mu) \frac{\partial}{\partial r}\left[\frac{1}{r} \frac{\partial}{\partial r}(r U)+\frac{\partial W}{\partial z}\right]=0 ; \\
& \mu \nabla^{2} W+(\lambda+\mu) \frac{\partial}{\partial z}\left[\frac{1}{r} \frac{\partial}{\partial r}(r U)+\frac{\partial W}{\partial z}\right]=0,
\end{aligned}
$$

де $U, W$ - відповідно радіальна та осьова компоненти вектору переміщення; $\mu, \lambda$ - коефіцієнти Ламе; $r, z$ - циліндричні координати; $\nabla^{2}$ - оператор Лапласа.

$$
\nabla^{2}=\frac{\partial^{2}}{\partial r^{2}}+\frac{1}{r} \frac{\partial}{\partial r}+\frac{1}{r^{2}} \frac{\partial^{2}}{\partial \varphi^{2}}+\frac{\partial^{2}}{\partial z^{2}}
$$
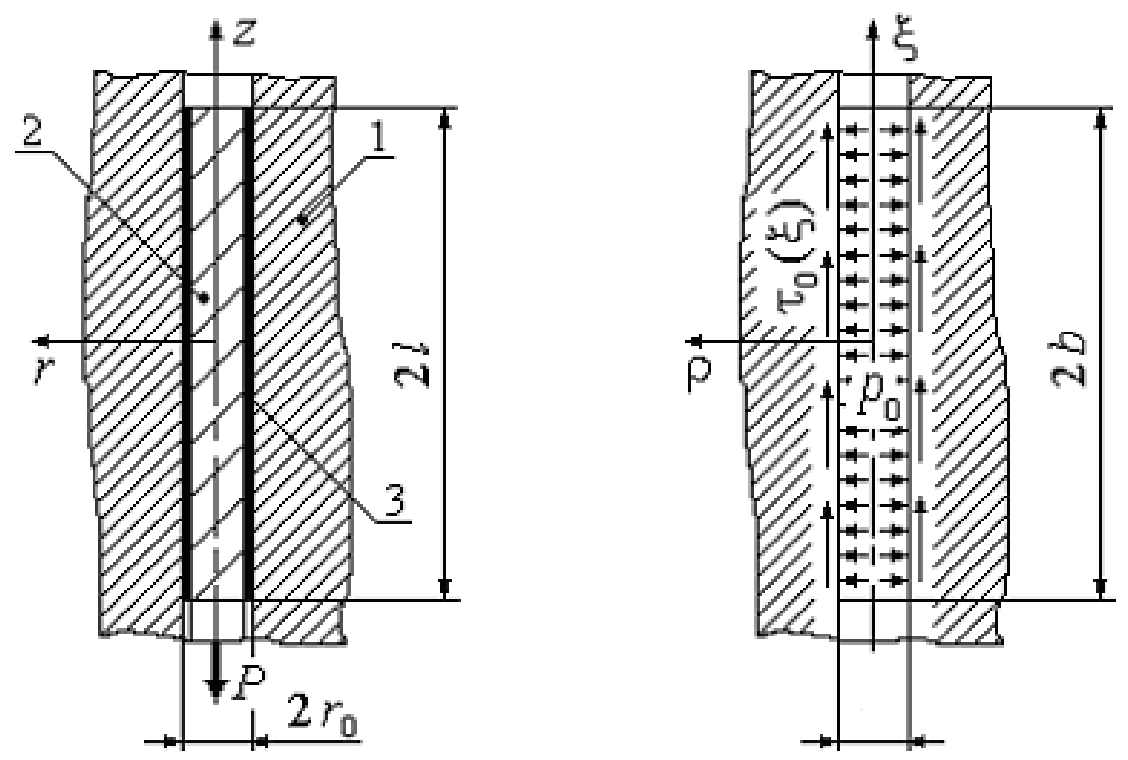

1- гірська порода, 2 - анкер, 3 - фіксуюча суміш

\section{Рисунок 6 - До постановки змішаної задачі теорії пружності}

Зробивши заміну змінних $\rho=r / r_{0}, \varsigma=\mathrm{z} / r_{0}$, будемо шукати розв'язок рівнянь (3) у формі Папковича-Нейбера

$$
\begin{aligned}
& U=4(1-v) B_{r}-\frac{\partial}{\partial \rho}\left(\rho B_{r}+\varsigma B_{z}+\frac{1}{r_{0}} B_{0}\right) \\
& W=4(1-v) B_{z}-\frac{\partial}{\partial \varsigma}\left(\rho B_{r}+\varsigma B_{z}+\frac{1}{r_{0}} B_{0}\right),
\end{aligned}
$$

де $B_{0}$ - гармонічний скаляр; $B_{r}, B_{z}$ - компоненти гармонічного вектора, які задовольняють рівнянням Лапласа 
ISSN 1607-4556 (Print), ISSN 2309-6004 (Online) Геотехнічна механіка. 2018. №142

$$
\nabla^{2} B_{0}=0 ; \quad \nabla^{2}\left(B_{r} e^{i \varphi}\right)=0 ; \quad \nabla^{2} B_{z}=0 .
$$

Крім того, гармонічні функції $B_{0}(\rho, \varsigma), B_{r}(\rho, \varsigma), B_{z}(\rho, \varsigma)$ повинні бути вибрані таким чином, щоб задовольнити граничним умовам

$$
\begin{aligned}
& \left.\sigma_{r}\right|_{\rho=1}=\left\{\begin{array}{cc}
-p_{0}, & |\varsigma| \leq b ; \\
0, & |\varsigma|>b ;
\end{array}\right. \\
& \left.\tau_{r z}\right|_{\rho=1}=\left\{\begin{array}{cc}
-\tau_{0}(\varsigma), & |\varsigma| \leq b ; \\
0, & |\varsigma|>b,
\end{array}\right.
\end{aligned}
$$

де $\sigma_{r}, \tau_{r z}-$ радіальний та дотичний компоненти тензору напружень; $b=l / r_{0}-$ відносна довжина зафіксованої ділянки; $p_{0}=\gamma H$ - тиск гірської породи на глибині $H$.

Дотичне напруження на поверхні анкерного шпуру визначимо як квадратичну функцію осьової координати

$$
\begin{aligned}
& \left.\tau\right|_{\rho=1}=\tau(\varsigma)=a_{0}+a_{1} \varsigma+a_{2} \varsigma^{2} ; \\
& \left.\tau\right|_{l=0}=\tau_{1} ;\left.\quad \tau\right|_{l=L}=\tau_{2},
\end{aligned}
$$

де $\tau_{1}, \tau_{2}$ - дотичні напруження на початку та кінці ділянки, що фіксує анкер $\left(\tau_{1}>\tau_{2}\right)$.

Тоді загальний розв’язок задачі запишеться у вигляді

$$
\begin{aligned}
& \sigma_{r}=-\frac{2}{\pi} \int_{0}^{\infty}\left[\left((3-2 v) K_{0}(\beta \rho)+\left(4(1-v) \frac{1}{\rho}+\beta \rho\right) K_{1}(\beta \rho)\right) \times\right. \\
& \times\left(\left(C_{1} p_{0} \sin (\beta b)-C_{2} a_{2}(\beta)\right) \cos (\beta \varsigma)+C_{2} a_{1}(\beta) \sin (\beta \varsigma)+\left(\beta K_{0}(\beta \rho)+\frac{1}{\rho} K_{1}(\beta \rho)\right) \times\right. \\
& \left.\times\left(\left(D_{1} p_{0} \sin (\beta b)-D_{2} a_{2}(\beta)\right) \cos (\beta \varsigma)+D_{2} a_{1}(\beta) \sin (\beta \varsigma)\right)\right] d \beta \\
& \sigma_{\varphi}=\frac{2}{\pi} \int_{0}^{\infty}\left[\left((1-2 v) \frac{\rho}{\beta} K_{0}(\beta \rho)+4(1-v) \frac{1}{\beta \rho} K_{1}(\beta \rho)\right) \times\right. \\
& \quad \times\left(\left(C_{1} p_{0} \sin (\beta b)-C_{2} a_{2}(\beta)\right) \cos (\beta \varsigma)+C_{2} a_{1}(\beta) \sin (\beta \varsigma)\right)+ \\
& \left.\quad+\frac{1}{\rho} K_{1}(\beta \rho)\left(\left(D_{1} p_{0} \sin (\beta b)-D_{2} a_{2}(\beta)\right) \cos (\beta \varsigma)+D_{2} a_{1}(\beta) \sin (\beta \varsigma)\right)\right] d \beta
\end{aligned}
$$


ISSN 1607-4556 (Print), ISSN 2309-6004 (Online) Геотехнічна механіка. 2018. №142

$$
\begin{aligned}
\sigma_{z}= & \frac{2}{\pi} \int_{0}^{\infty}\left[\left(\beta \rho K_{1}(\beta \rho)-2 v K_{0}(\beta \rho)\right) \times\right. \\
& \times\left(\left(C_{1} p_{0} \sin (\beta b)-C_{2} a_{2}(\beta)\right) \cos (\beta \varsigma)+C_{2} a_{1}(\beta) \sin (\beta \varsigma)\right)+ \\
& \left.+\beta K_{0}(\beta \rho)\left(\left(D_{1} p_{0} \sin (\beta b)-D_{2} a_{2}(\beta)\right) \cos (\beta \varsigma)+D_{2} a_{1}(\beta) \sin (\beta \varsigma)\right)\right] d \beta \\
\tau_{r z}= & \frac{2}{\pi} \int_{0}^{\infty}\left[\left(\beta \rho K_{0}(\beta \rho)+2(1-v) K_{1}(\beta \rho)\right) \times\right. \\
& \times\left(-\left(C_{1} p_{0} \sin (\beta b)-C_{2} a_{2}(\beta)\right) \cos (\beta \varsigma)+C_{2} a_{1}(\beta) \sin (\beta \varsigma)\right)+ \\
& \left.+\beta K_{1}(\beta \rho)\left(-\left(D_{1} p_{0} \sin (\beta b)-D_{2} a_{2}(\beta)\right) \sin (\beta \varsigma)+D_{2} a_{1}(\beta) \cos (\beta \varsigma)\right)\right] d \beta
\end{aligned}
$$

Вирази для переміщень у радіальному напряму і вздовж осі симетрії при цьому набувають вигляду

$$
\begin{aligned}
U= & \frac{r_{0}}{\pi \mu_{0}} \int_{0}^{\infty}\left[\left(4(1-v) \frac{\rho}{\beta} K_{1}(\beta \rho) / \beta+\rho K_{0}(\beta \rho)\right) \times\right. \\
& \times\left(\left(C_{1} p_{0} \sin (\beta b)-C_{2} a_{2}(\beta)\right) \cos (\beta \varsigma)+C_{2} a_{1}(\beta) \sin (\beta \varsigma)\right)+ \\
& \left.+K_{1}(\beta \rho)\left(\left(D_{1} p_{0} \sin (\beta b)-D_{2} a_{2}(\beta)\right) \cos (\beta \varsigma)+D_{2} a_{1}(\beta) \sin (\beta \varsigma)\right)\right] d \beta ; \\
W= & r_{0} \int_{0}^{\infty}\left[\left(\rho K_{1}(\beta \rho)\right)\left(\left(C_{1} p_{0} \sin (\beta b)-C_{2} a_{2}(\beta)\right) \sin (\beta \varsigma)-C_{2} a_{1}(\beta)\right) \cos (\beta \varsigma)+\right. \\
& \left.+K_{0}(\beta \rho)\left(\left(D_{1} p_{0} \sin (\beta b)-D_{2} a_{2}(\beta)\right) \sin (\beta \varsigma)-D_{2} a_{1}(\beta) \cos (\beta \varsigma)\right)\right] d \beta .
\end{aligned}
$$

Для визначення напружено-деформованого стану у околі анкерного шпуру 3 врахуванням конструктивних параметрів анкера використовувалось послідовне рішення двох задач. Розв'язок першої задачі дозволив визначати зусилля і дотичні напруження на контактних поверхнях оболонки із ФС ( для цього використано модифікований розв'язок узагальненої задачі М.С. Жуковського), Використання функції розподілу дотичних напружень у якості граничної умови для другої задачі, наведеної вище, дозволило визначати компоненти тензора напружень в околі анкерного шпуру.

Порівняння результатів, отриманих в у такій постановці, з рішенням цієї ж задачі у МСЕ постановці дозволили його використання з задовільною для інженерних розрахунків точністю.

Для з'ясування ступеня впливу на функцію параметрів необхідно виконати іiі відтворення у аналітичній формі, тобто у вигляді формули. Побудова функції в аналітичній формі здійснюється методами, які використовують їі значення на сітці параметрів. За невеликої кількості параметрів і незначних витрат часу на отримання значень функції у вузлі такої сітки побудова функції можлива з використанням методів апроксимації. Для більш складних задач отримання таб- 
лиці значень вихідної функції на сітці параметрів потребує значних обчислювальних витрат, що іноді унеможливлює процес її відтворення.

Використання відтвореної у аналітичній формі функції для оцінки впливу параметрів накладає вимоги на форму іiі представлення. Вимоги до форми представлення функції $\epsilon$ протилежними. Так, з одного боку, відтворена функція повинна забезпечувати якомога більшу точність, тобто бути наближеною до реально заданої функції, а з іншого, дати змогу здійснити оцінку впливу кожного параметра на процес .

Використання модифікованого розв'язку узагальненої задачі М.Є. Жуковського для проведення практичних розрахунків параметрів пов'язане $з$ деякими складностями обчислювального характеру. Справа полягає у тому, що залежність між силовими параметрами на контактуючих поверхнях описується гіперболічними функціями (2). Для зручності користування такими залежностями у практичній діяльності доцільно було б представити їх у вигляді добутку степеневих функцій, кожна з яких залежала б від одного параметра. Представлення залежностей у такій формі дозволило б не тільки виконувати обчислення у більш простий спосіб, але й оцінити ступінь впливу параметрів на контактні зусилля.

Враховуючи особливу важливість шару ФС у механізмі передачі навантажень від анкерної штанги до гірського масиву, розглянемо у якості функції величину зусиль, що виникають в оболонці з ФС

$$
\sigma_{v y}^{p}=\frac{1}{L} \int_{0}^{L} \sigma_{v t}(\xi) d \xi
$$

де $\sigma_{v t}=\sigma\left(L, q, d_{a}, d_{v t}, E_{a}, E_{v t}, h_{a}, h_{v t}\right)=\sum_{i=1}^{k-1}\left(p_{i}-t_{i}\right) ; L-$ довжина ділянки оболонки із ФС, у поперечному перерізі якої знаходяться зусилля; $q$ - величина попереднього навантаження анкерної штанги; $d_{a}, d_{v}$, діаметри анкерної штанги та анкерного шпуру; $E_{a}, E_{v t}$ - модулі пружності матеріалу анкерної штанги та ФС; $h_{a}, h_{v t}-$ кроки періодичних виступів на поверхнях анкерної штанги та оболонки is $\Phi C$.

Спробуємо у виявити степінь впливу цих параметрів на величину зусиль в оболонці із ФС. Для вирішення поставленої задачі скористаємось розробленим методом. Навантаження на контактних поверхнях «анкерна штанга $-\Phi С »-p_{k}$ та «ФС - гірська порода» $-t_{k}$ визначаються згідно формул (2). Використання методу до вказаної задачі дозволило отримати залежність функції $\sigma_{v t}$ від параметрів $q, d_{a}, d_{v t}, E_{a}, E_{v}, h_{a}, h_{v t}$ і $L$, а саме

$$
\sigma_{v t}=a_{L} q \frac{d_{v t}^{3,94531}}{d_{a}^{4,08821}} \frac{E_{v t}^{0,861906}}{E_{a}^{0,455547}} \frac{h_{a}^{2,54292}}{h_{v t}^{1,56405}} \frac{1}{L^{0,998028}},
$$


де $a_{L}-$ коефіцієнт апроксимації. У більш зручному вигляді формулу можна представити як

$$
\sigma_{v t}=\varphi\left(q, d_{a}, d_{v t}, E_{a}, E_{v t}, h_{a}, h_{v t}, L\right)=a_{L} q \frac{d_{v t}^{4}}{d_{a}^{4}} \frac{E_{v t}^{1}}{E_{a}^{1}} \frac{h_{a}^{3}}{h_{v t}^{2}} \frac{1}{L}
$$

Слід зауважити, що проблема вибору класів функцій апроксимації є однією 3 найважливіших проблем не тільки прикладної математики, а й технічних застосувань. Як свідчать роботи [6], коефіцієнт варіації апроксимуючих функцій не може виступати у якості критерію вибору функцій. У якості критерію, який обмежує вибір класу апроксимуючих функцій обрано розмірність вихідної функції. Використання цієї теорії для обмеження класу апроксимуючих функцій $є$ вкрай важливим для оцінювання впливу параметрів на результативну функцію.

Спробуємо виявити закономірності впливу вихідних параметрів, зокрема, величини попереднього навантаження $P$, глибини розташування виробки $H$, робочої довжини $L$ та діаметрів шпуру $d_{v t}$, анкерної штанги $d_{a}$ та інтенсивності дотичних напружень на радіус впливу анкера $\rho$ [2].

Радіус впливу $\rho=f\left(P, H, L, d_{v t}, I_{p}^{r}, d_{a}\right) \in$ неперервною відносно перелічених параметрів функцією, а $I_{p}^{z}-\epsilon$ середньо інтегральне значення інтенсивності дотичних напружень. Застосування методу дозволило встановити залежність між параметрами та ступенем їх впливу на радіус дії анкеру або відстань між анкерами

$$
\rho\left(P, H, L, I_{p}^{r}, d_{a}\right)=a_{d_{v}} \sqrt[3]{\frac{P H d_{a}}{L I_{p}^{r}}}
$$

де $a_{d_{a}}-$ коефіцієнт апроксимації.

Визначитись $з$ проблемою вибору функції допомагає згадуваний раніше критерій - теорія розмірності.

Максимальні значення відносних похибок у визначенні функції на границі області їі визначення і не перевищували 7 \%. Мінімальні ж значення похибок знаходились в центральній частині області визначення.

Слід зазначити, що радіус впливу є пропорційним жорсткості системи, що збігається з висновками [7] про обернений характер залежності від довжини анкеру і підтверджує правильність отриманої залежності.

Висновки.

1. Метод послідовної апроксимації, запропонований для визначення закономірностей між параметрами системи, підтвердив свою працездатність.

Відносні похибки для більшості параметрів не перевищують 7 \%, що є підтвердженням працездатності алгоритму, з одного боку, і можливості користування спрощеними формулами для інженерних розрахунків, з другого. 
2. Встановлено залежність зусиль, що виникають у тілі оболонки із фіксуючої суміші, від параметрів $q, d_{a}, d_{v t}, E_{a}, E_{v t}, h_{a}, h_{v t}, l$.

3. Встановлено залежність між відстанню між анкерами та глибиною розташування виробки, величиною попереднього навантаження анкерних штанг, довжиною та їх діаметрами і діаметрами шпурів, що використовуються для кріплення гірничих виробок.

\section{СПИСОК ЛИТЕРАТУРЫ}

1. Canbulat I. Evaluation and design of optimum support systems in South African collieries using the probabilistic design approach / Dissertation submitted to the Fuculty of Engineering Built Environment and Technology for the degree Philosophy Doctor/ University of Pretiria. Pretoria, 2008. $340 \mathrm{p}$.

2. Ларіонов Г.І. Оцінювання конструктивних параметрів анкерного кріплення. Дніпропетровськ :Національна металургійна академія України, 2011.286 c.

3. Larionov G.I., Larionov N.G. Evaluating of metal-resin anchor parameters influence on the support capacity / Geotechnical Processes During Underground Mining 2012, Tailor\&Francis Group, London. pp.189-194...

4. Larionov G.I., Kirija R., Braginec D. On parameters influence evaluating method application in some geotechnical tasks / Mining of Mineral Deposites. 2013. P.247-255.

5. Dey A., Aziz N.I., Indraratna B. Shear behaviour of infilled bolted joint / AIMS (Aachen International Mining Symposia), 6 and 7 Junlay, 2001. P. 323-341.

6. Ивахненко А.Г., Юрачковский Ю.П. Моделирование сложных систем по экспериментадьным данням. - М.: Радио и Связь, 1987. $118 \mathrm{c}$.

7. Mark C. Design of roof bolt systems / New technology for coal mine roof support. 2000. №2000-151. P.156.

\section{REFERENCES}

1. Canbulat, I. (2008), "Evaluation and design of optimum support systems in South African collieries using the probabilistic design approach", Dissertation submitted to the Fuculty of Engineering Built Environment and Technology for the degree Philosophy Doctor, University of Pretiria, Pretoria, South Africa.

2. Larionov, H.I. (2011), Otsinyavannya konstruktyvnykh parametriv ankernogo kriplennya [Estimation of structural parameters of anchor support], Dnipropetrovsk, Ukraine.

3. Larionov, G.I. and Larionov, N.G. (2012), "Evaluating of metal-resin anchor parameters influence on the support capacity", Geotechnical Processes During Underground Mining. pp.189-194...

4. Larionov, G.I., Kiriya, R. and Braginec, D. (2013), "On parameters influence evaluating method application in some geotechnical tasks", Mining of Mineral Deposites, p.247-255.

5. Dey, A., Aziz, N.I. and Indraratna, B. (2011), "Shear behaviour of infilled bolted joint", Aachen International Mining Symposia, p. 323-341.

6. Ivakhnenko, A.H. and Yurachkovsky, Yu.P. (1987), Modelirovanie slozhnykh system po eksperimentalnym dannym [Modeling of complex systems by experimental data], Radio i svyaz, Moscow, Russia.

7. Mark, C. (2000), "Design of roof bolt systems", New technology for coal mine roof support, no. 2000-151, P.156.

\section{Про авторів}

Ларіонов Грігорій Іванович, доктор технічних наук, старший науковий співробітник, старший науковий співробітник відділу Фізико-механічних основ гірничого транспорту, Інститут геотехнічної механіки ім. М.С. Полякова Національної академії наук України (IГTM HАН України), Дніпро, Україна, GILarionov@nas.gov.ua.

Ларіонов Микола Григорович, магістр, співробітник відділу Фізико-механічних основ гірничого транспорту, Інститут геотехнічної механіки ім. М.С. Полякова Національної академії наук України (ІГТМ НАН України), Дніпро, Україна, GILarionov@nas.gov.ua.

\section{About the authors}

Larionov Grigoriy Ivanovych, Doctor of Technical Sciences (D.Sc.), Senior Researcher, Senior Researcher in Department of Mining Transport Physics and Mechanics, M.S. Polyakov Institute of Geotechnical Mechanics NAS of Ukraine (IGTM, NAS of Ukraine), Dnipro, Ukraine, GILarionov@nas.gov.ua.

Larionov Mykola Grigorovych, Master of Sciences (M.S.), Department of Mining Transport Physics and Mechanics, M.S. Polyakov Institute of Geotechnical Mechanics NAS of Ukraine (IGTM, NAS of Ukraine), Dnipro, Ukraine, GILarionov@nas.gov.ua.

Annotation. In the paper the application of point estimation of the results obtained by numerical methods is considered. The result of the point evaluation is an analytical expression in the form of the product of the independent functions of one variable. The expression is used to analyze the behavior of the function in the neighborhood of the point being studied. As model, for the demonstration of the proposed method, the problem of representing a number of ele- 
mentary functions with an estimate of their errors is considered. An example of using this approach to the specification is given. The conclusion about the possibility of applying this approach to solving an important scientific problem of determining the step of arrangement of anchors is taken into account taking into account the transfer mechanism in the "anchor-fixing mixture-rock" system. The method of sequential approximation, proposed to determine the regularities between the parameters of the system, confirmed its efficiency.

Relative errors for most parameters do not exceed $7 \%$, which is a confirmation of the efficiency of the algorithm, on the one hand, and the possibility of using simplified formulas for engineering calculations, on the other. The system of parameters for assessing the stress-strain state is determined by solving two problems. From the solution of the modified generalized problem M.E. Zhukovsky determined the distribution of tangential stresses on the surface of the well. Next, it was used as the boundary conditions for determining the zone of distribution of the stress-strain state in the vicinity of the anchor. This approach allowed to obtain the dependence of the step of arrangement of anchors, taking into account the depth of occurrence of mining, preliminary tension of anchors, length, its diameter, intensity of tangential stresses. The radius of influence is proportional to the stiffness of the system, which coincides with the conclusions of other scientists about the inverse nature of the dependence on the length of the anchor and confirms the correctness of the obtained dependence.

Keywords: metal-polymer anchor, estimation, stress-deformed state, system, independent functions, radius of influence.

Аннотация. В работе рассмотрено применение точечной оценки результатов, полученных численными методами. Результат точечной оценки представляет собой аналитическое выражение в виде произведения независимых функций одной переменной. Выражение применяется для анализа поведения функции в окрестности исследуемой точки. В качестве модельных для демонстрации предлагаемого метода рассмотрены задачи о предоставлении ряда элементарных функций с оценкой их погрешностей. Приведен пример использования указанного подхода к техническому заданию. Сделан вывод о возможности применения данного подхода к решению важной научной проблемы - определения шага расстановки анкеров с учетом механизма передачи в системе «анкерфиксирующая смесь-горная порода». Метод последовательной аппроксимации, предложенный для определения закономерностей между параметрами системы, подтвердил свою работоспособность.

Относительные погрешности для большинства параметров не превышают 7\%, что является подтверждением работоспособности алгоритма, с одной стороны, и возможности пользования упрощенными формулами для инженерных расчетов, с другой. Система параметров для оценки напряженно-деформированного состояния определяется путем решения двух задач. Из решения модифицированной обобщенной задачи М.Е. Жуковского определялось распределение касательных напряжений на поверхности скважины. Далее оно использовалось в качестве граничных условий для определения зоны распространения напряженно-деформированного состояния в окрестности анкера. Такой подход позволил получить зависимость шага расстановки анкеров с учетом глубины залегания горной выработки, предварительного натяжения анкеров, длины, его диаметра, интенсивности касательных напряжений. Радиус действия является пропорциональным жесткости системы, что совпадает с выводами других ученых об обратном характере зависимости от длины анкера, и подтверждает правильность полученной зависимости.

Ключевые слова: металлополимерный анкер, оценка, напряженно-деформированное состояние, система, независимые функции, радиус действия. 